\title{
Is there a role for resection of oligometastatic disease in pancreatic ductal adenocarcinoma?
}

\author{
Yana Puckett ${ }^{1}$, Mariam F. Eskander ${ }^{2}$, Christopher T. Aquina², Timothy M. Pawlik ${ }^{2}$ \\ 'Department of Surgery, West Virginia University School of Medicine, Charleston, WV 25340, USA. \\ ${ }^{2}$ Department of Surgical Oncology, The Ohio State University, Columbus, OH 43210, USA.
}

Correspondence to: Prof. Timothy M. Pawlik, Department of Surgery, The Urban Meyer III and Shelley Meyer Chair for Cancer Research, The Ohio State University, Wexner Medical Center, 395 W. 12th Ave, Suite 670, Columbus, OH 43210, USA.

E-mail: tim.pawlik@osumc.edu

How to cite this article: Puckett Y, Eskander MF, Aquina CT, Pawlik TM. Is there a role for resection of oligometastatic disease in setting of pancreatic ductal adenocarcinoma? J Cancer Metastasis Treat 2020;6:44.

http://dx.doi.org/10.20517/2394-4722.2020.98

Received: 11 Aug 2020 First Decision: 15 Sep 2020 Revised: 30 Sep 2020 Accepted: 14 Oct 2020 Published: 11 Nov 2020

Academic Editor: Lucio Miele Copy Editor: Cai-Hong Wang Production Editor: Jing Yu

\begin{abstract}
It is estimated that approximately $80 \%-90 \%$ of pancreatic ductal adenocarcinoma (PDAC) will present with unresectable disease with about half of patients presenting with distant metastases. The prognosis of these patients is generally poor with an average life expectancy of approximately 6 months and a median 5 -year survival of $1 \%$. The current standard of care for metastatic PDAC patients is palliative chemotherapy, as surgery in this setting does not lead to better survival. More recently, some centers have utilized very specific patient selection to perform resection of oligometastatic disease with reported improvement in survival - with many centers using response to systemic therapy as a sign of favorable biology. We performed a literature review investigating the role of surgical resection of oligometastatic disease of the lung and liver in PDAC.
\end{abstract}

Keywords: Pancreatic cancer, pancreatic ductal adenocarcinoma, liver metastasis, oligometastatic disease, M1, surgery, metastasectomy

\section{INTRODUCTION}

Pancreatic ductal adenocarcinoma (PDAC) accounts for approximately 3\% of all cancers and about $8 \%$ of all cancer deaths in the United States ${ }^{[1]}$. Despite improvements in surgical technique and chemotherapy regimens, the 5-year relative survival for pancreatic cancer has only increased from $3 \%$ to $9 \%$ over the last

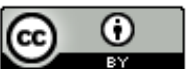

(C) The Author(s) 2020. Open Access This article is licensed under a Creative Commons Attribution 4.0 International License (https://creativecommons.org/licenses/by/4.0/), which permits unrestricted use sharing, adaptation, distribution and reproduction in any medium or format, for any purpose, even commercially, as long as you give appropriate credit to the original author(s) and the source, provide a link to the Creative Commons license, and indicate if changes were made. 

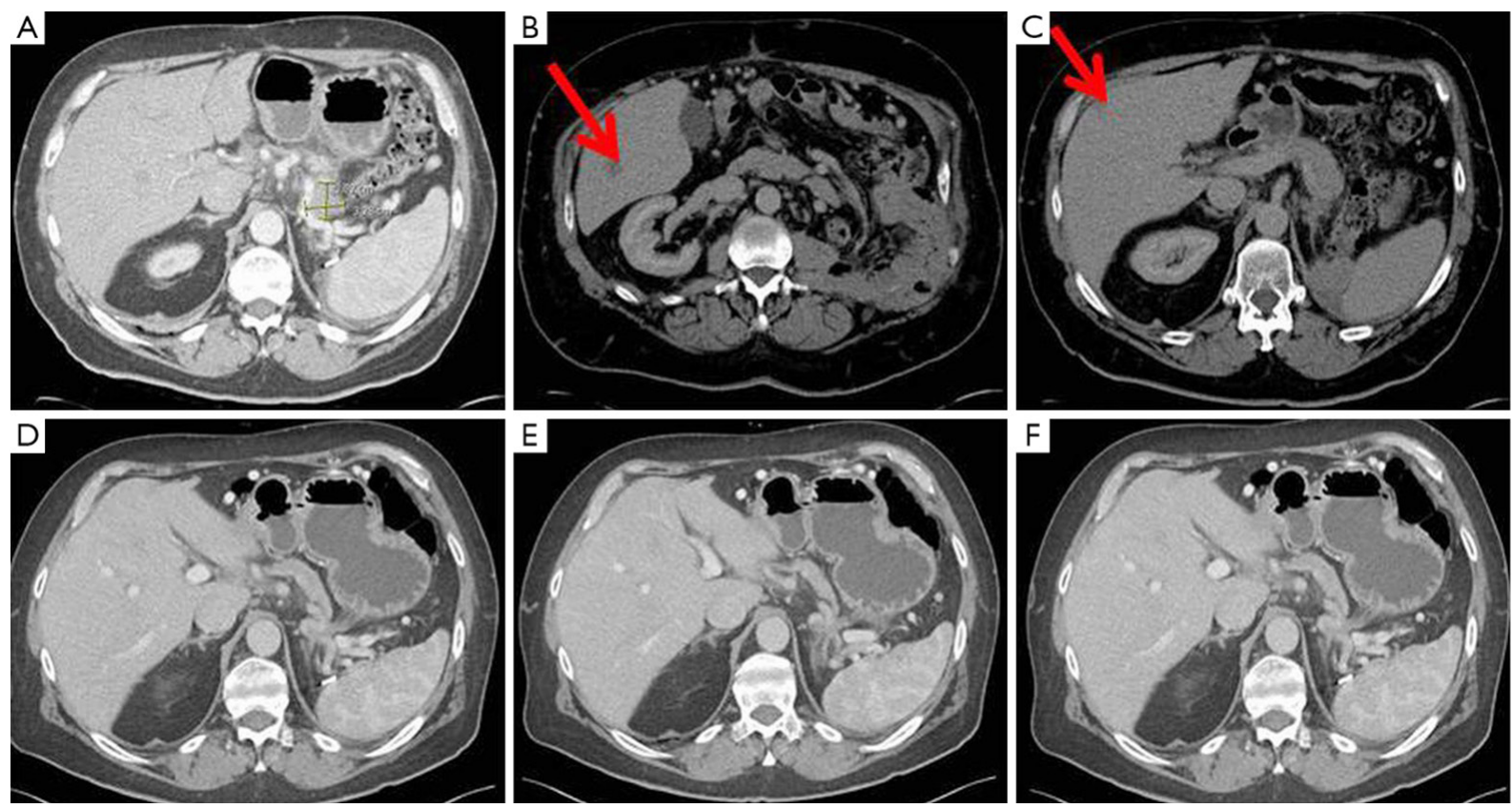

Figure 1. Sixty-six year-old man diagnosed with: biopsy-proven PDAC seen on CT (A); the patient also had synchronous biopsy-proven liver metastases ( $B$ and $C$, red arrows); he underwent neoadjuvant chemotherapy with 5-FU, leucovorin, oxaliplatin, and irinotecan with radiologic response 24 months after diagnosis (D-F). Surgical resection of the pancreas and liver lesions was performed as a one-stage procedure. The patient remained disease-free 30 months post-resection ${ }^{[7]}$. PDAC: pancreatic ductal adenocarcinoma; CT: computed tomography; 5-FU: 5-fluorouracil

35 years $^{[1,2]}$. The majority of PDAC is diagnosed when the cancer has spread to distant sites or has become unresectable $e^{[3,4]}$. The term oligometastastases, coined in 1995 by Hellman and Weichselbaum, refers to the existence of metastases that are few in number ${ }^{[5]}$. In 2019, Damanakis et al. ${ }^{[6]}$ proposed a definition for oligometastatic disease in pancreatic cancer that included anatomic as well as biological criteria to identify a subset of patients with favorable biology and improved prognosis who may be candidates for surgery. Damanakis restricted the cohort to patients with "limited disease," defined as 4 or fewer hepatic or pulmonary metastatic lesions, as well as only individuals with a Carbohydrate antigen 19-9 (CA 19-9) of less than $1,000 \mathrm{U} / \mathrm{mol}$. In addition, only patients who responded to systemic chemotherapy were included. With these restricted criteria, the investigators identified a subset of about $8 \%$ of patients from the original cohort with metastatic disease who had improved overall survival with resection.

Traditionally, oligometastatic disease in the context of PDAC has been associated with a poor prognosis with an average life expectancy of approximately 6 months and a median 5 -year overall survival of $1 \%{ }^{[7]}$. Surgical resection of oligometastatic disease in pancreatic cancer is generally not associated with prolonged survival. The National Comprehensive Cancer Network treatment guidelines do not, therefore, consider these patients to be surgical candidates ${ }^{[8]}$. However, the topic has been much debated, and some centers have performed resection of PDAC metastases and have published data advocating for this approach in very select patients [Figure 1 $]^{[5,8-10]}$.

A review on resection of PDAC metastasis published in 2006 reported a median survival ranging from 4 to 6 months with a 5 -year survival of zero ${ }^{[4]}$. Nevertheless, potential utility of resecting oligometastatic disease has been suggested based on outcomes after palliative R2 resection. For example, a study by Bockhorn et al. ${ }^{[1]}$ demonstrated a survival benefit for patients who underwent an R2 resection versus versus bypassed patients (11.5 vs. 7.5 months). However, patients who underwent an resection experienced increased morbidity such as longer hospital stay, and 2 patients out of 40 died perioperatively. These data suggested that debulking of 
disease in select patients may be associated with a possible prolonged and have served to encourage other investigators to consider surgical removal of oligometastatic disease.

Metastatic PDAC most commonly involves the liver, followed by inter-aortocaval lymph nodes (ILN), lung, and peritoneum ${ }^{[7,12]}$. However, distant metastasis in patients with PDAC has been documented in almost every organ based on autopsy studies ${ }^{[13-19]}$. Surgical resection of liver and lung oligometastases with negative margins can be technically feasible depending on the anatomic location; however, decisions regarding oligometastasectomy should be based on predictions about tumor biology and careful patient selection. Surgical resection of liver metastases may be safely accomplished at the time of pancreatic resection in select patients, while pulmonary metastases can often be performed in a minimally invasive fashion after primary pancreatic resection. In general, resection of oligometastatic PDAC lesions should be done in a staged fashion after systemic chemotherapy that has demonstrated stable or responsive disease.

We herein performed a literature review of studies investigating whether there is a role for surgical resection with curative intent of limited PDAC metastases to the lung or liver. The focus of this literature review was on pulmonary and hepatic metastases given that the majority of available literature on oligometastasectomy in PDAC is focused primarily on those two organs.

\section{HEPATIC METASTASECTOMY}

The liver is the most common location of PDAC metastases due to the proximity of the liver and blood supply to the pancreas ${ }^{[20,21]}$. Approximately $70 \%$ of patients with metastatic PDAC have disease in the liver. Among these patients, $30 \%$ have limited disease ${ }^{[22]}$. While resection of colorectal liver metastasis is safe and provides a survival benefit, the resection of liver metastases in non-colorectal patients, including pancreatic cancer patients, has not been widely accepted ${ }^{[2]}$. Because national guidelines do not recommend resection of a primary tumor along with synchronous liver metastases, research on the topic is lacking ${ }^{[23]}$. The general treatment approach to liver metastases in PDAC is systemic chemotherapy and/or radiation therapy ${ }^{[24]}$. In addition, locoregional ablative techniques such as percutaneous radiofrequency ablation and microwave ablation have been recognized as safe and less invasive alternatives to surgery with comparable recurrence and survival outcomes ${ }^{[25-27]}$.

In a study by Hackert et al. ${ }^{[9]}$, a total of 128 patients underwent surgery for oligometastatic PDAC with spread to either the liver ( 85 patients) or ILN (43 patients) [Table 1]. Among these patients, 20 had received neoadjuvant treatment. The patients underwent a variety of procedures including pancreaticoduodenectomy, distal pancreatectomy, total pancreatectomy with splenectomy, extended lymphadenectomy, bisegmentectomy, right hepatectomy, segmental liver resection ranging from 1-4 segments, and extended right hepatectomy. Overall, $72.9 \%$ of the liver resections were performed at the time of primary pancreatic resection with the rest performed following pancreatic resection at an average of 18.4 months later. The majority of the liver metastases resected were less than $2 \mathrm{~cm}$ in diameter, and $96.4 \%$ of patients had more than three metastatic lesions in the liver. Twenty patients had undergone neoadjuvant treatment prior to resection; data on adjuvant therapy was only available for 95 patients, 73 of whom completed adjuvant therapy. Surgical morbidity and 30 -day mortality rates were $45.0 \%$ and $2.9 \%$ for the whole cohort, respectively. Median overall survival was 12.3 months with a 5 -year overall survival of $8.1 \%$ after liver resection and $10.1 \%$ after ILN resection. There was no survival difference detected between patients that received neoadjuvant treatment and those that did not. The number of liver metastases, size of liver metastases, and pre-operative CA 19-9 levels were not significantly associated with survival. There was also no significant difference in overall survival between synchronously and metachronously resected patients when survival was analyzed from time of liver resection.

A multi-institutional European study performed by Tachezy et al. ${ }^{[28]}$ examined a total of 69 patients with $\mathrm{PDAC}$ and synchronous liver metastases who underwent combined pancreas and liver resections compared 
Table 1. Summary of most recent studies of PDAC patients undergoing metastasectomy for liver metastases

\begin{tabular}{|c|c|c|c|c|c|c|c|c|c|}
\hline Authors & Type of Study & Year & Chemotherapy & $n$ & $\begin{array}{l}\text { Morbidity } \\
\text { (\%) }\end{array}$ & $\begin{array}{c}\text { 30-day } \\
\text { mortality } \\
(\%)\end{array}$ & $\begin{array}{c}\text { Median } \\
\text { OS } \\
\text { (months) }\end{array}$ & $\begin{array}{c}\text { 2-year } \\
\text { survival } \\
\text { (months) }\end{array}$ & $\begin{array}{c}\text { 5-year } \\
\text { survival } \\
\text { (months) }\end{array}$ \\
\hline Hackert et al. ${ }^{[9]}$ & $\begin{array}{l}\text { Single Center } \\
\text { Retrospective }\end{array}$ & 2017 & $\begin{array}{l}20 \text { patients received } \\
\text { neoadjuvant } \\
\text { chemotherapy; } 73 \\
\text { patients completed } \\
\text { adjuvant chemotherapy }\end{array}$ & $\begin{array}{l}85 \\
\text { (liver) } \\
43 \\
(I L N)\end{array}$ & 45.0 & 2.9 & $\begin{array}{l}12.3 \\
12.3\end{array}$ & $\mathrm{~N} / \mathrm{A}$ & $\begin{array}{l}8.1 \% \\
10.1 \%\end{array}$ \\
\hline Michalski et al. ${ }^{[10]}$ & $\begin{array}{l}\text { Systematic review } \\
\text { of } 3 \text { case reports } \\
\text { and } 18 \text { studies }\end{array}$ & 2008 & $\mathrm{~N} / \mathrm{A}$ & 103 & $24.1-26.0$ & $0.0-4.3$ & $5.8-11.4$ & $\mathrm{~N} / \mathrm{A}$ & $\mathrm{N} / \mathrm{A}$ \\
\hline Tachezy et al. ${ }^{[28]}$ & $\begin{array}{l}\text { Retrospective } \\
\text { review of } 6 \text { centers }\end{array}$ & 2015 & $\begin{array}{l}100 \% \text { received } \\
\text { neoadjuvant } \\
\text { chemotherapy }\end{array}$ & 69 & 68.0 & 1.0 & 13.6 & $N / A$ & $\mathrm{~N} / \mathrm{A}$ \\
\hline Frigerio et al. ${ }^{[29]}$ & $\begin{array}{l}\text { Retrospective } \\
\text { review of } 2 \text { centers }\end{array}$ & 2017 & $\begin{array}{l}100 \% \text { received } \\
\text { neoadjuvant } \\
\text { chemotherapy }\end{array}$ & 24 & 62.0 & 0.0 & 56.0 & $\mathrm{~N} / \mathrm{A}$ & $\mathrm{N} / \mathrm{A}$ \\
\hline Klein et al. ${ }^{[30]}$ & $\begin{array}{l}\text { Single Center } \\
\text { Retrospective }\end{array}$ & 2012 & $\begin{array}{l}100 \% \text { received adjuvant } \\
\text { chemotherapy }\end{array}$ & 22 & 18.0 & 0 & 7.6 & 5.0 & 0.0 \\
\hline
\end{tabular}

PDAC: pancreatic ductal adenocarcinoma; ILN: interaortocaval lymph nodes; N/A: not applicable; OS: overall survival

to patients who were explored but not resected. The overall survival was longer in the resected group (13.6 vs. 7 months, $P<0.001)$ for pancreatic head tumors. However, there was no survival benefit for distal pancreatic tumors (14 vs. 15 months, $P=0.312$ ).

A 2017 retrospective study from Italy used the strategy of downstaging via neoadjuvant chemotherapy ${ }^{[29]}$. About 5\% of the initial cohort who had synchronous liver oligometastatic disease met the criteria of disappearance of liver metastasis and decreased CA 19-9. Ro resection was achieved in 88\% of patients with a 17\% complete pathologic response. Overall survival was 56 months and disease-free survival 27 months. The authors concluded that carefully selected patients fully responsive to neoadjuvant chemotherapy may be cautiously selected for surgery.

Alternatively, some studies have not shown a survival benefit. A single-center study by Klein et al. $^{[30]}$ Germany studied the outcomes of 22 patients with PDAC and synchronous hepatic metastases who underwent combined pancreatic resection and liver-directed therapy compared to matched non-metastatic PDAC patients who underwent surgical resection. A third of the patients with liver metastasis underwent segmentectomy and the remainder enucleation. The matched groups had similar complication rates; however, the two-year survival rate for the metastatic group was a dismal 5\% (one patient), and no patients survived 5 years.

The only systematic review to date on resection of isolated hepatic metastases in PDAC was published in 2008 and therefore included older studies than this current review. The study was comprised of 3 case reports and 18 retrospective single center studies for a pooled number of 103 cases. The great majority of the studies included less than 10 patients. The overall morbidity and mortality ranged between $24.1 \%-26.0 \%$ and $0-4.3 \%$, respectively. Median survival ranged between 5.8 and 11.4 months $^{[10]}$.

\section{PULMONARY METASTASECTOMY}

The lung is another frequent area of oligometastases in PDAC with potential for surgical resection to achieve negative margins [Figure 2]. While there is a clear survival benefit to pulmonary metastasectomy in colorectal cancer patients ${ }^{[31-35]}$, the data is not certain for PDAC patients [Table 2].

A study by Arnaoutakis et al. ${ }^{[34]}$ reported improved median survival for patients with isolated pulmonary metastases from PDAC undergoing pulmonary resections with low morbidity and mortality. This study 
Table 2. Summary of most recent studies of PDAC patients undergoing metastasectomy for lung metastases

\begin{tabular}{|c|c|c|c|c|c|c|c|c|}
\hline Authors & Type of Study & Year & $n$ & Morbidity (\%) & $\begin{array}{c}\text { 30-day } \\
\text { mortality (\%) }\end{array}$ & $\begin{array}{c}\text { Median OS } \\
\text { (months) }\end{array}$ & $\begin{array}{l}\text { 2-year survival } \\
\text { (months) }\end{array}$ & $\begin{array}{l}\text { 5-year survival } \\
\text { (months) }\end{array}$ \\
\hline Arnaotakis et al. ${ }^{[34]}$ & $\begin{array}{l}\text { Single Center } \\
\text { Retrospective }\end{array}$ & 2011 & 9 & $0 \%$ & $0 \%$ & 51.0 & $40 \%$ & $N / A$ \\
\hline Robinson et al. ${ }^{[36]}$ & $\begin{array}{l}\text { Single Center } \\
\text { Retrospective }\end{array}$ & 2016 & 29 & $0 \%$ & $0 \%$ & 29.0 & N/A & N/A \\
\hline Downs-Canner et al. ${ }^{[37]}$ & $\begin{array}{l}\text { Single Center } \\
\text { Retrospective }\end{array}$ & 2015 & 78 & N/A & N/A & 35.6 & N/A & 18.3 \\
\hline Yamashita et al. ${ }^{[38]}$ & $\begin{array}{l}\text { Single Center } \\
\text { Retrospective }\end{array}$ & 2015 & 2 & N/A & $\mathrm{N} / \mathrm{A}$ & 70.0 & N/A & N/A \\
\hline
\end{tabular}

PDAC: pancreatic ductal adenocarcinoma; N/A: not applicable; OS: overall survival
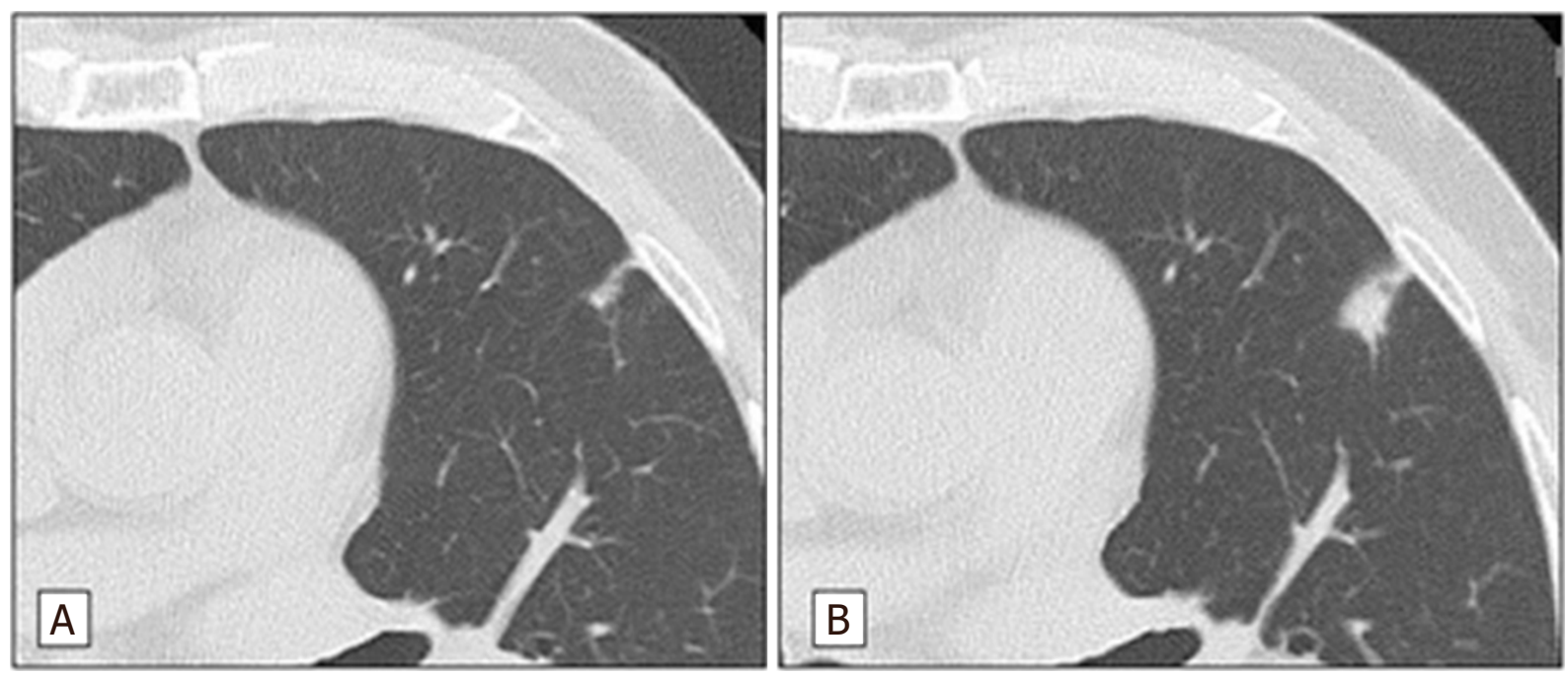

Figure 2. $C T$ chest showing isolated pulmonary metastases initially diagnosed $(A) 98$ months after curative resection of PDAC and then (B) 108 months after curative resection of PDAC, showing that the nodule increased in size. The patient underwent wedge resection and received gemcitabine-based adjuvant chemotherapy for 6 months. The patient remained asymptomatic and tumor-free for a total of 4 years since last pulmonary metastasectomy ${ }^{[40]}$. CT: computed tomography; PDAC: pancreatic ductal adenocarcinoma

included 9 patients who underwent pulmonary metastasectomy after initial pancreatectomy for stage I or II PDAC (median time from pancreatectomy to pulmonary metastasectomy of 34 months) compared to a matched reference group who did not undergo lung resection. The majority of the patients received adjuvant chemotherapy and radiation. Median overall survival for the pulmonary metastasectomy group was 51 months compared to 23 months for the reference group, $P=0.04$. There were no complications or in-hospital mortality after pulmonary metastasectomy.

A more recent study on isolated pulmonary metastasectomy for PDAC showed similar results. The cohort included 29 patients who had previously undergone resection of pancreatic cancer who subsequently underwent lung resection, 55\% for isolated pancreatic cancer lung metastases and 45\% for primary lung cancer. Median disease-free interval was 24 months for the pulmonary metastasectomy group $v s .8$ months for the non-metastasectomy patients. Median overall survival after lung resection was 28 months for the pulmonary metastasectomy group, corresponding to an estimated 5-year overall survival of $37 \%$. There was no post-operative morbidity or mortality ${ }^{[36]}$.

Downs-Canner et al. ${ }^{[37]}$ evaluated all patients with pulmonary metastases from PDAC at a high-volume institution in the United States to determine the natural history of this disease process. Median survival for patients with lung-first metastasis was significantly longer than for patients with synchronous abdominallung metastases or abdominal-first disease. Among patients who underwent pancreatic resection and then 
developed lung-only disease, survival was significantly longer (67.5 months) for patients who received surgical resection or stereotactic radiosurgery $(n=8)$ compared to chemotherapy (33.8 months) or observation (29.9 months).

Similarly, another study by Yamashita et al. ${ }^{[38]}$ identified 142 resected PDAC patients, 14 of whom developed isolated pulmonary recurrence. Patients who had isolated pulmonary recurrence had significantly longer survival than those with metastatic disease to other locations ( 40.3 vs. 20.9 months, $P=0.0156)$. The two patients who underwent pulmonary metastasectomy survived for 70 months after resection.

Overall, a small amount of retrospective data shows improved survival for staged resection of isolated pulmonary metastases in PDAC, especially if combined with adjuvant chemotherapy and/or radiation. The data also suggests that lung-only metastatic disease may be more indolent than metastatic disease in other locations making it a reasonable target for metastasectomy in select patients.

\section{CONCLUSION}

As recurrence and liver metastasis associated with resected pancreatic cancer is quite high and most systemic regimens only improve survival by a few months, resection of oligometastatic disease may be reasonable in very carefully selected patients. Furthermore, as systemic chemotherapy becomes more effective, the ability to treat patients with oligometastatic disease, as well as select patients who may benefit from resection may improve. As molecular data emerge, targeted approaches informed by the underlying genetic profile of a specific pancreatic tumor may also help to tailor more personalized approaches to therapy.

Although the current standard of care for metastatic pancreatic adenocarcinoma is palliative chemotherapy with no role for surgical resection, single institution experiences suggest that there may be a survival benefit for resection of oligometastatic disease in select patients. Some centers have created algorithms to select patients with more favorable tumor biology who might benefit from resection, applying such parameters as response to chemotherapy and CA 19-9 values. It appears that morbidity and mortality is slightly higher for hepatic compared with pulmonary metastatic resection. If surgery is being considered for oligometastatic disease, surgical resection should be combined with systemic and patients need to very carefully selected.

There are no randomized controlled trials exist, and current data are based on small, retrospective observational studies with varying definitions of oligometastasis and different inclusion criteria, extent of metastasectomy, timing and regimens of systemic therapy, and reference groups for comparison. As such, the level of evidence to suggest a benefit for resection of oligometastatic disease remains low.

Of note, there is an ongoing multicenter, randomized, controlled phase III trial called CSPAC-1 (NCT03398291) in China evaluating the possible benefit of simultaneous resection of pancreatic cancer and liver oligometastases after induction chemotherapy ${ }^{[39]}$. Inclusion criteria include age 18-75, Eastern Cooperative Oncology Group performance status 0-1, and histologically-confirmed stage IV pancreatic cancer with no more than 3 liver metastases. Patients who meet inclusion criteria for intervention, including resectable primary tumor and liver lesions, no new metastatic disease, and a drop in abnormal tumor markers by more than $50 \%$ after chemotherapy, are eligible for synchronous resection of the primary pancreatic cancer and the liver metastasis. Patients will randomized to chemotherapy and resection versus standard chemotherapy. The primary outcome measure is overall survival from start of induction chemotherapy, and secondary outcomes include overall survival after completing induction chemotherapy, quality of life, and post-operative morbidity and mortality. The expected completion date of the study is 2025. Until randomized data are available, resection of oligometastatic disease of the liver and lung in PDAC should only be done in a multi-disciplinary setting for highly selected patients and, preferably, on a protocol basis. 


\section{DECLARATIONS}

\section{Authors' contributions}

Made substantial contributions to conception and design of the literature review: Puckett Y, Pawlik TM

Performed literature review and manuscript preparation: Puckett Y, Eskander MF, Aquina CT

Responsible for conception and design of literature review: Pawlik TM

\section{Availability of data and materials}

Not applicable.

\section{Financial support and sponsorship}

None.

\section{Conflicts of interest}

All authors declared that there are no conflicts of interest.

\section{Ethical approval and consent to participate}

Not applicable.

\section{Consent for publication}

Not applicable.

\section{Copyright}

(c) The Author(s) 2020.

\section{REFERENCES}

1. Siegel RL, Miller KD, Jemal A. Cancer statistics, 2020. CA Cancer J Clin 2020;70:7-30.

2. Greenlee RT, Murray T, Bolden S, Wingo PA. Cancer statistics, 2000. CA Cancer J Clin 2000;50:7-33.

3. Nentwich MF, Bockhorn M, Konig A, Izbicki JR, Cataldegirmen G. Surgery for advanced and metastatic pancreatic cancer--current state and trends. Anticancer Res 2012;32:1999-2002.

4. Mann O, Strate T, Schneider C, Yekebas EF, Izbicki JR. Surgery for advanced and metastatic pancreatic cancer--current state and perspectives. Anticancer Res 2006;26:681-6.

5. Treasure T. Oligometastatic cancer: an entity, a useful concept, or a therapeutic opportunity? J R Soc Med 2012;105:242-6.

6. Damanakis AI, Ostertag L, Waldschmidt D, et al. Proposal for a definition of "Oligometastatic disease in pancreatic cancer". BMC Cancer 2019;19:1261.

7. Lu F, Poruk KE, Weiss MJ. Surgery for oligometastasis of pancreatic cancer. Chin J Cancer Res 2015;27:358-67.

8. Tempero MA, Malafa MP, Al-Hawary M, et al. Pancreatic Adenocarcinoma, Version 2.2017, NCCN Clinical Practice Guidelines in Oncology. J Natl Compr Canc Netw 2017;15:1028-61.

9. Hackert T, Niesen W, Hinz U, et al. Radical surgery of oligometastatic pancreatic cancer. Eur J Surg Oncol 2017;43:358-63.

10. Michalski CW, Erkan M, Huser N, Muller MW, Hartel M, Friess H, Kleeff J. Resection of primary pancreatic cancer and liver metastasis: a systematic review. Dig Surg 2008;25:473-80.

11. Bockhorn M, Cataldegirmen G, Kutup A, et al. Crossing the Rubicon: when pancreatic resection with curative intent ends in an R2 status. Impact of "desmoplastic pseudo-pancreatitis" and anatomical site of irresectability. Ann Surg Oncol 2009;16:1212-21.

12. D'Haese JG, Renz BW, Ilmer M, Werner J. Surgery for isolated local recurrence and metachronous oligometastasis in pancreatic cancer. Chirurg 2020;91:628-35.

13. Yamamoto S, Sato Y, Takeishi T, et al. Liver transplantation in an endostage cirrhosis patient with abdominal compartment syndrome following a spontaneous rectus sheath hematoma. J Gastroenterol Hepatol 2004;19:118-9.

14. Van Oudheusden TR, Grull H, Dankers PY, De Hingh IH. Targeting the peritoneum with novel drug delivery systems in peritoneal carcinomatosis: a review of the literature. Anticancer Res 2015;35:627-34.

15. Sugarbaker PH. Strategies to improve local control of resected pancreas adenocarcinoma. Surg Oncol 2017;26:63-70.

16. Staribratova D, Zaprianov Z, Uchikov A. Adenocarcinoma of the pancreas with distant meningeal metastasis. Khirurgiia (Sofiia) 2009:4851.

17. Maeno T, Satoh H, Ishikawa H, et al. Patterns of pancreatic metastasis from lung cancer. Anticancer Res 1998;18:2881-4.

18. Kocic M, Nikolic S, Zegarac M, et al. Prognostic factors and outcomes of cytoreductive surgery combined with hyperthermic intraperitoneal chemotherapy in patients with advanced ovarian cancer - A single tertiary institution experience. $J$ BUON 2016;21:1176- 
83.

19. Embuscado EE, Laheru D, Ricci F, et al. Immortalizing the complexity of cancer metastasis: genetic features of lethal metastatic pancreatic cancer obtained from rapid autopsy. Cancer Biol Ther 2005;4:548-54.

20. Tsurusaki M, Numoto I, Oda T, et al. Assessment of Liver Metastases Using CT and MRI Scans in Patients with Pancreatic Ductal Adenocarcinoma: Effects of Observer Experience on Diagnostic Accuracy. Cancers (Basel) 2020;12.

21. Danet IM, Semelka RC, Nagase LL, Woosely JT, Leonardou P, Armao D. Liver metastases from pancreatic adenocarcinoma: MR imaging characteristics. J Magn Reson Imaging 2003;18:181-8.

22. Renz BW, Boeck S, Roeder F, Trumm C, Heinemann V, Werner J. Oligometastatic Disease in Pancreatic Cancer - How to Proceed? Visc Med 2017;33:36-41.

23. Tempero MA. NCCN Guidelines Updates: Pancreatic Cancer. J Natl Compr Canc Netw 2019;17:603-5.

24. Hasuike Y, Tanigawa T, Yamada M, et al. A case report-advanced pancreas cancer with liver and lung metastases well controlled over one year by combination therapy with systemic chemotherapy, radiation and hepatic arterial infusion in an outpatient setting. Gan To Kagaku Ryoho 2008;35:2117-9.

25. Schullian P, Johnston EW, Putzer D, et al. Stereotactic radiofrequency ablation (SRFA) for recurrent colorectal liver metastases after hepatic resection. Eur J Surg Oncol 2020;S0748-7983(20)30806-4.

26. Lee SJ, Kim JH, Kim SY, Won HJ, Shin YM, Kim PN. Percutaneous Radiofrequency Ablation for Metachronous Hepatic Metastases after Curative Resection of Pancreatic Adenocarcinoma. Korean J Radiol 2020;21:316-24.

27. Sparchez Z, Mocan T, Hajjar NA, et al. Percutaneous ultrasound guided radiofrequency and microwave ablation in the treatment of hepatic metastases. A monocentric initial experience. Med Ultrason 2019;21:217-24.

28. Tachezy M, Gebauer F, Janot M, et al. Synchronous resections of hepatic oligometastatic pancreatic cancer: Disputing a principle in a time of safe pancreatic operations in a retrospective multicenter analysis. Surgery 2016;160:136-44.

29. Frigerio I, Regi P, Giardino A, et al. Downstaging in Stage IV Pancreatic Cancer: A New Population Eligible for Surgery? Ann Surg Oncol 2017;24:2397-403.

30. Klein F, Puhl G, Guckelberger O, et al. The impact of simultaneous liver resection for occult liver metastases of pancreatic adenocarcinoma. Gastroenterol Res Pract 2012;2012:939350.

31. Alghamdi AA, Hasabullah MA, Alhusani AI, et al. Survival Outcome of Pulmonary Metastasectomy Among Patients with Sarcoma and Colorectal Primary Cancers: A Single Institute Experience. Gulf J Oncolog 2018;1:56-60.

32. Nanji S, Karim S, Tang E, et al. Pulmonary metastasectomy for colorectal cancer: predictors of survival in routine surgical practice. Ann Thorac Surg 2018;105:1605-12.

33. Ampollini L, Gnetti L, Goldoni M, et al. Pulmonary metastasectomy for colorectal cancer: analysis of prognostic factors affecting survival. $J$ Thorac Dis 2017;9:S1282-S90.

34. Arnaoutakis GJ, Rangachari D, Laheru DA, et al. Pulmonary resection for isolated pancreatic adenocarcinoma metastasis: an analysis of outcomes and survival. J Gastrointest Surg 2011;15:1611-7.

35. Klempnauer J, Ridder GJ, Piso P, Pichlmayr R. Is liver resection in metastases of exocrine pancreatic carcinoma justified? Chirurg 1996;67:366-70.

36. Robinson LA, Tanvetyanon T, Springett G, et al. Pulmonary metastasectomy for suspected pancreaticobiliary cancer. J Thorac Cardiovasc Surg 2016;152:75-82.

37. Downs-Canner S, Zenati M, Boone BA, et al. The indolent nature of pulmonary metastases from ductal adenocarcinoma of the pancreas. J Surg Oncol 2015;112:80-5.

38. Yamashita K, Miyamoto A, Hama N, Asaoka T, Maeda S, Omiya H, Takami K, Doki Y, Mori M, Nakamori S. Survival Impact of Pulmonary Metastasis as Recurrence of Pancreatic Ductal Adenocarcinoma. Dig Surg 2015;32:464-71.

39. Wei M, Shi S, Hua J, Xu J, Yu X, Chinese Study Group for Pancreatic C. Simultaneous resection of the primary tumour and liver metastases after conversion chemotherapy versus standard therapy in pancreatic cancer with liver oligometastasis: protocol of a multicentre, prospective, randomised phase III control trial (CSPAC-1). BMJ Open 2019;9:e033452.

40. Matsuki R, Sugiyama M, Takei H, et al. Long-term survival with repeat resection for lung oligometastasis from pancreatic ductal adenocarcinoma: a case report. Surg Case Rep 2018;4:26. 